\title{
Exploiting Synergistic Effects in Organozinc Chemistry for Direct Stereoselective C-Glycosylation Reactions at Room Temperature
}

\author{
Alberto Hernán-Gómez, ${ }^{a}$ Samantha A. Orr, ${ }^{a}$ Marina Uzelac, ${ }^{a}$ Alan R. Kennedy, ${ }^{a}$ Santiago Barroso, ${ }^{b}$ \\ Xavier Jusseau, ${ }^{\text {b }}$ Sébastien Lemaire, ${ }^{\text {b }}$ Vittorio Farina ${ }^{* b}$ and Eva Hevia ${ }^{* a}$
}

Dedication ((optional))

\begin{abstract}
Pairing a range of bis(aryl) zinc reagents $\mathrm{ZnAr}_{2}$ with the stronger Lewis acidic [(ZnAr $\left.\left.F_{2}\right)\right] \quad\left(A r^{F}=C_{6} F_{5}\right)$, enables highly stereoselective cross-coupling between glycosyl bromides and $\mathrm{ZnAr}_{2}$ without the use of a transition metal. Reactions occur at room temperature with excellent levels of stereoselectivity, where $\mathrm{ZnAr}_{2}{ }_{2}$ acts as a non-coupling partner although its presence is crucial for the execution of the $C\left(s p^{2}\right)-C\left(s p^{3}\right)$ bond formation process. Mechanistic studies have uncovered a unique synergistic partnership between the two zinc reagents, which circumvents the need for transition-metal catalysis or forcing reaction conditions. Key to the success of the coupling is the avoidance of solvents that act as Lewis bases vs. diarylzinc compounds (e.g. THF).
\end{abstract}

Cross-coupling reactions between organic halides and organozinc nucleophiles, typified by the Negishi reaction, are amongst the most synthetically powerful and widely used methods for the construction of $\mathrm{C}-\mathrm{C}$ bonds. ${ }^{[1]}$ The use of transition metal catalysis, most commonly employing palladium or nickel systems, is usually imperative to facilitate these couplings. ${ }^{[2]}$ However, recent advances focusing on the development of more sustainable and more economical synthetic strategies have shown that in certain cases organozinc compounds can actually participate in direct $\mathrm{C}-\mathrm{C}$ bond formation For example, albeit under harsh reaction conditions $\left(90-130^{\circ} \mathrm{C}\right.$, $24 \mathrm{~h}$ ), direct cross-couplings of aryl halides with bis(aryl)zinc reagents have been reported by Uchiyama and Wang. ${ }^{[3]}$ Also extendable to organoaluminium reagents, ${ }^{[4]}$ these processes are thought to occur via a single-electron-transfer (SET) mechanism. In addition, Lemaire and co-workers have reported the direct stereoselective arylation of glycosyl bromides using arylzinc reagents, also under quite vigorous conditions (temperatures of $90-100^{\circ} \mathrm{C}$ ). ${ }^{[5]}$ Complementary to this work, Ingleson has described the efficient room-temperature method for $\mathrm{C}\left(\mathrm{sp}^{2}\right)-\mathrm{C}\left(\mathrm{sp}^{3}\right)$ cross-coupling of a range of diarylzinc reagents with benzyl and alkyl halides. In agreement with Lemaire's work, this study also stresses that the success of the coupling heavily depends on the use of non-polar, non-coordinating solvents. ${ }^{[6]}$ Thus, the presence of ethereal solvents such as THF or $\mathrm{Et}_{2} \mathrm{O}$ dramatically slows down the reactions, ${ }^{[6]}$ While these results illustrate the ability of arylzinc reagents to engage in cross-

[a] Dr. A. Hernán-Gómez, Dr. S. A. Orr, Dr. M. Uzelac, Dr. A. R. Kennedy, Prof. E. Hevia

WestCHEM, Department of Pure and Applied Chemistry, University of Strathclyde, 295 Cathedral Street, Glasgow, G1 1XL, (UK) E-mail: eva.hevia@strath.ac.uk

[b] Dr. S. Barroso, Dr. X. Jusseau, Dr. S. Lemaire and Dr. V. Farina Pharmaceutical Development and Manufacturing Sciences, Janssen Pharmaceutica, Turnhoutseweg 30, B-2340 Beerse, Belgium.

Supporting information for this article is given via a link at the end of the document. coupling without the need of transition-metal catalysis, no mechanistic information is available on how these reactions actually occur.

In our aim to fill this knowledge gap, focusing on the synthesis of pharmaceutically relevant $C$-glycosides,${ }^{[7]}$ herein we combine NMR spectroscopic studies with kinetic investigations to provide mechanistic insights into transition-metal-free crosscoupling reactions using bis(aryl)zinc reagents. Furthermore, by systematically probing the effect of additives in these reactions, we disclose a new stereoselective method to access aryl-Cglycosides which is based on the synergistic partnership of a range of $\mathrm{ZnAr}_{2}$ nucleophiles with the strongly Lewis acidic bis(pentafluorophenyl)zinc complex $\operatorname{ZnAr}_{2}{ }_{2}\left(\mathrm{Ar}^{\mathrm{F}}=\mathrm{C}_{6} \mathrm{~F}_{5}\right)$, while operating at room temperature.

Our initial studies on the couplings of $\mathrm{ZnAr}_{2}$ reagents with glycosyl bromide 1 were carried out using a 1:1 mixture of di-nbutyl ether (DBE) and toluene. In these reactions the arylzinc reagents were generated in situ by salt metathesis of $\mathrm{ZnBr}_{2}$ with two equivalents of the relevant LiAr species, and therefore 2 equiv $\mathrm{LiBr}$ is also present in the reaction mixture. Although the target $C$-arylated glycosides were obtained in good yields (50$86 \%$ ), forcing reaction conditions were required. ${ }^{[5 a]}$ Building on the solvent effects just described, we then assessed the reactivity of salt-free $\mathrm{ZnPh}_{2}$ (purified by sublimation) using neat toluene as the reaction medium (Fig 1). Interestingly, under these conditions, the coupling reaction to form $2 \mathbf{a}$ occurs smoothly at room temperature and is complete in less than 5 hours $(95 \%$ yield) with a high level of stereoselectivity $(\beta / \alpha$ ratio of $89: 11$, Fig 1a; Table 1, entry 1 ).

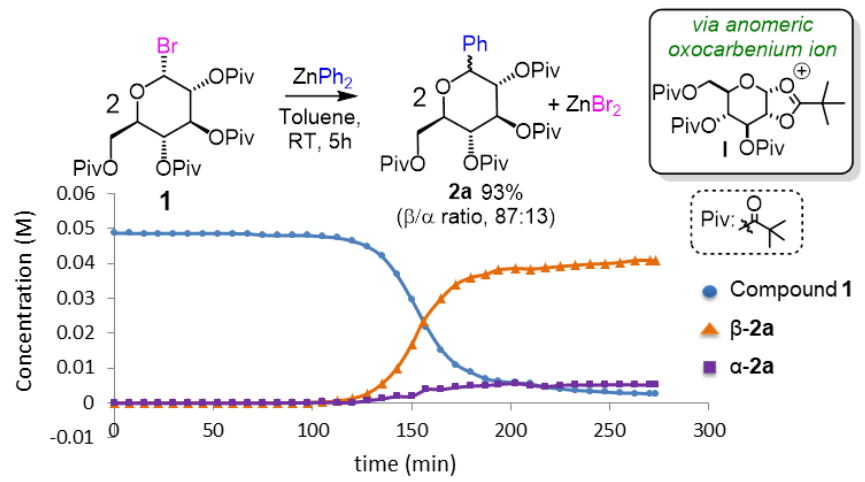

Figure 1. (a) Synthesis of 2a via coupling of 1 and $\mathrm{ZnPh}_{2}$. (b) Kinetic plot for the formation of $2 a$ and consumption of 1 over time obtained by ${ }^{1} \mathrm{H}$ NMR monitoring of the reaction of $1(0.048 \mathrm{M})$ with $\mathrm{ZnPh}_{2}(0.024 \mathrm{M})$ in $\left[\mathrm{D}_{8}\right]-\mathrm{Tol}$ at 298 K.

Although this selectivity is slightly lower than that observed previously using the diarylzinc generated in situ in the DBE:toluene solvent mixture, ${ }^{[4 a]}$ such selectivity can be rationalised in similar terms, by invoking participation of the neighbouring pivaloyl group via bicyclic oxocarbenium ion $\mathbf{I}$. 
DOSY NMR spectroscopic studies of $\mathrm{ZnPh}_{2}$ in $\mathrm{DBE} / \mathrm{d}_{8}$-tol solutions indicate the formation of adduct $\left[\mathrm{ZnPh}_{2}(\mathrm{DBE})\right] .{ }^{[8]}$ Thus, the significantly slower coupling reactivity observed using $\mathrm{DBE} /$ toluene as a solvent may be due to the generation of a less reactive, more coordinatively saturated, DBE- $\mathrm{ZnPh}_{2}$ adduct, hinting at the initial interaction of the $\mathrm{ZnAr}_{2}$ with 1 as a key step to induce the formation of $\mathrm{I}$. Consistent with this interpretation, using [ $\mathrm{ZnPh}_{2}$ (TMEDA)], (TMEDA $=N, N, N$ ', $N^{\prime}$-tetramethylethane1,2-diamine), where $\mathrm{N}$-donor TMEDA is tightly bonded to $\mathrm{Zn}$, the formation of $2 \mathrm{a}$ was totally inhibited. ${ }^{[9]}$

${ }^{1} \mathrm{H}$ NMR monitoring of the coupling reaction to give $2 \mathrm{a}$ showed that reaction rate is represented by a sigmoidal curve, with a long induction time of over 2 hours (Fig 1b), suggesting autocatalytic behaviour. A possible rationale could be that the reaction is catalysed by $\mathrm{ZnBr}_{2}$ generated as a byproduct from the reaction of $\mathrm{ZnPh}_{2}$ with 1. Being a stronger Lewis acid than $\mathrm{ZnPh}_{2}, \mathrm{ZnBr}_{2}$ could then activate 1, promoting formation of the proposed reactive intermediate cation I (Fig 1) by abstraction of bromide to form zincate anion $\left\{\mathrm{ZnBr}_{3}\right\}$. This hypothesis gained further support when 1 was reacted with an equimolar mixture of $\mathrm{ZnPh}_{2}$ and $\mathrm{ZnBr}_{2}$ (Table 1, entry 2). Whereas $\mathrm{ZnBr}_{2}$ is sparingly soluble in toluene and it is therefore difficult to estimate its concentration in this solvent, the coupling reaction is significantly faster $(2 \mathrm{~h}, 70 \%$ yield) and little or no induction period is observed (see SI for details). The possible involvement of Grignard-like $\mathrm{PhZnBr}$ as a Lewis acid (instead of $\mathrm{ZnBr}_{2}$ ) cannot be disregarded, as it will also be present in solution, in variable amounts, due to the Schlenk-type equilibrium (Eq 1). ${ }^{[11]}$

\section{$\mathrm{ZnPh}_{2}+\mathrm{ZnBr}_{2} \rightleftharpoons 2 \mathrm{PhZnBr} \quad(\mathrm{Eq} 1)$}

Interestingly, when the reaction was carried out in neat toluene using the ammonium salt $\mathrm{NBu}_{4} \mathrm{Br}$ (TBAB, 1 eq) as an additive, formation of $2 a$ is completely inhibited (Table 1 , entry 3 ). We later found that TBAB forms a readily isolable, anionically activated zincate, $\left\{\mathrm{NBu}_{4}\right\}\left\{\mathrm{ZnPh}_{2} \mathrm{Br}\right\} \quad(3)(\mathrm{Fig} 2)^{[12]}$ This result highlights the crucial role of the Lewis acid in the reaction media.

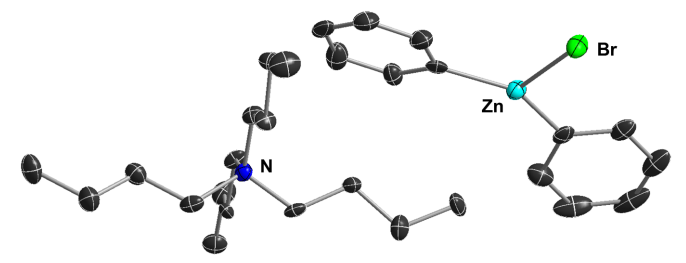

Figure 2. Molecular structure of $\left\{\mathrm{NBu}_{4}\right\}\left\{\mathrm{ZnPh} \mathrm{Br}_{2}\right\}$ (3) with thermal ellipsoids at $30 \%$ probability. Hydrogens are omitted for clarity.

Capitalising on these findings, we next pondered whether addition of an external Lewis acid could also favour these couplings, eliminating the need of an induction period (Fig 1). We probed the related bis(aryl)zinc complex, $\mathrm{ZnAr}_{2}{ }_{2}$ (4), where the pull of highly electron withdrawing $\mathrm{C}_{6} \mathrm{~F}_{5}$ should greatly enhance the Lewis acidity of the $\mathrm{Zn}$ centre. Pleasingly, when 1 (2 eq) was reacted with an equimolar mixture of $\mathrm{ZnPh}_{2}$ and 4, 2a was obtained selectively in a $99 \%$ yield offering similar stereoselectivity as when $\mathrm{ZnPh}_{2}$ was used, but in just under one hour (Table 1, entry 4). Interestingly, no transfer of $\mathrm{Ar}^{\mathrm{F}}$ unit was observed, which demonstrates the stronger nucleophilicity of $\mathrm{ZnPh}_{2}$ versus 4 vis a vis oxocarbenium intermediate I. In fact, experiments monitoring a 2:1 mixture of 1 and $\mathbf{4}$ in $\left[\mathrm{D}_{8}\right]$-toluene over $24 \mathrm{~h}$ show that the latter is completely inert towards crosscoupling under the conditions studied.

Table 1. Direct arylation of 1 with $\mathrm{ZnPh}_{2}$ in the presence of additives ${ }^{[a]}$.

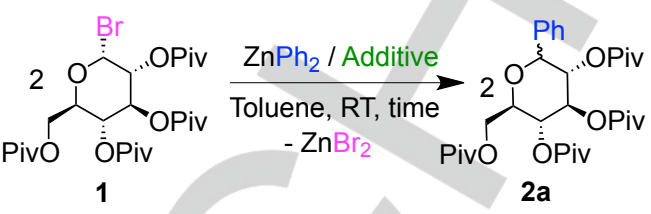

\begin{tabular}{|c|c|c|c|c|}
\hline Entry & Additive $^{[\mathrm{a}]}$ & $\begin{array}{c}\text { Time } \\
\text { (h) }\end{array}$ & $\begin{array}{l}\text { Yield } \\
(\%)^{[b]}\end{array}$ & $\begin{array}{c}\beta / \alpha \\
\text { ratio }\end{array}$ \\
\hline 1 & None & 4.5 & 95 & $89 / 11$ \\
\hline 2 & $\mathrm{ZnBr}_{2}(1 \mathrm{eq})$ & 2 & 70 & $91 / 9$ \\
\hline 3 & $\mathrm{NBu}_{4} \mathrm{Br}(1 \mathrm{eq})$ & 24 & 0 & - \\
\hline 4 & $\mathrm{ZnAr}_{2}{ }_{2}(1$ eq $)$ & 1 & 99 & $87 / 13$ \\
\hline 5 & $\mathrm{ZnAr}_{2}{ }_{2}(50 \mathrm{~mol} \%)$ & 1.5 & 99 & $86 / 14$ \\
\hline 6 & $\mathrm{ZnAr}_{2}^{\mathrm{F}}{ }_{2}(20 \mathrm{~mol} \%)$ & 2 & 99 & $86 / 14$ \\
\hline 7 & $\operatorname{ZnAr}_{2}{ }_{2}(10 \mathrm{~mol} \%)$ & 2.5 & 94 & $88 / 12$ \\
\hline 8 & $\mathrm{ZnAr}_{2}{ }_{2}(1 \mathrm{eq}), \mathrm{DBE}(1 \mathrm{eq})$ & 3.7 & 98 & $90 / 10$ \\
\hline
\end{tabular}

${ }^{[\mathrm{a}]}$ Conditions: 1 (0.048 M), $\mathrm{ZnPh}_{2}(0.024 \mathrm{M}),\left[\mathrm{D}_{8}\right]-\mathrm{Tol}, 25^{\circ} \mathrm{C} .{ }^{[\mathrm{b}]}$ Yields were determined by ${ }^{1} \mathrm{H}$ NMR spectroscopy using hexamethylcyclotrisiloxane as internal standard.

${ }^{1} \mathrm{H}$ NMR monitoring of the coupling of 1 (2 eq) with a 1:1 mixture of $\mathrm{ZnPh}_{2}$ and $\mathbf{4}$ showed not only that $\mathbf{4}$ is unreacted at the conclusion of the experiment, but also that no induction period is required and a first order decay is observed (Fig 3). This made us consider whether 4 might also operate under a catalytic regime. However, when sub stoichiometric amounts of $\mathbf{4}$ where employed, the reactions were significantly slower and sigmoidal behavior for the formation of 2 was observed (Table 1, entries 57). ${ }^{[10]}$ This could be due partly to the possible competing cocomplexation of $\mathbf{4}$ with product $\mathbf{2 a}$ to form a deactivated coordination adduct, i.e. product inhibition. ${ }^{[13]}$

Consistent with the solvent effects noted before, introducing oxygen donor ligand DBE resulted in a noticeable deceleration of the reaction rate (Table 1 , entry 8 ). ${ }^{[10]}$ This is probably due to the formation of less active coordination adducts $\left[\mathrm{DBE}\left(\mathrm{ZnAr}_{2}\right)\right],{ }^{[14]}$ which ultimately diminishes the amount of solvent-free 4 available for generating oxocarbenium $\mathbf{I}$.

These findings suggest that the enhanced reactivity using equimolar mixtures of the $\mathrm{ZnPh}_{2} / 4$ combination can be rationalised in terms of both arylzinc reagents operating in a unique cooperative manner, with $\mathbf{4}$ activating the glycosyl bromide, facilitating formation of anomeric cation I which subsequently can be arylated, presumably by $\mathrm{ZnPh}_{2}$. The mild reaction conditions and high levels of stereoselectivity obtained contrast with those previously reported in the literature using transition metal catalysts which require longer reaction times (up to $12 \mathrm{~h}$ ), proceed in lower yields, and often offer lower stereoselective control. ${ }^{[15,16]}$ To confirm that our observed 
reactivity can be unequivocally attributed to the zinc reagents, ICP-MS analysis of $\mathrm{ZnPh}_{2}$ and $\mathbf{4}$ were carried out, which showed extremely low concentrations ${ }^{[17]}$ of trace transition-metal impurities active in $\mathrm{C}-\mathrm{C}$ bond formation processes.
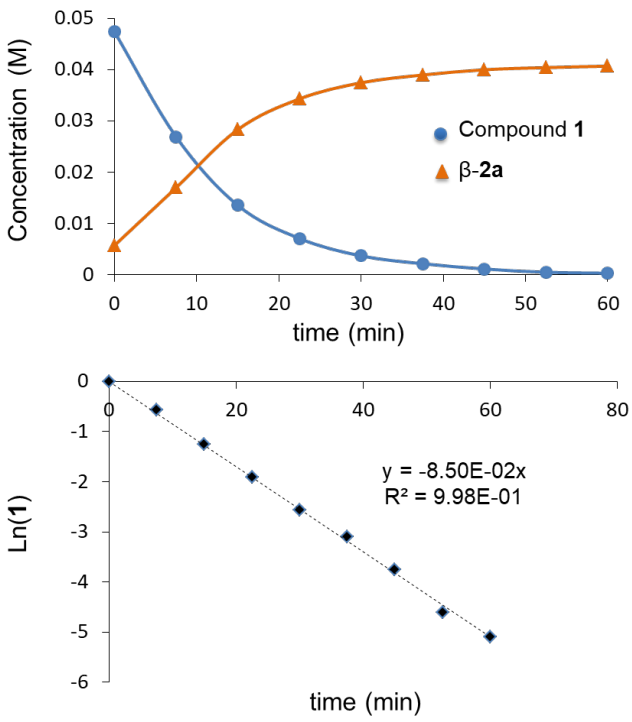

Figure 3. (Coupling reaction of $1(0.048 \mathrm{M})$ and $\mathrm{ZnPh}_{2} / \mathrm{ZnAr}_{2}^{\mathrm{F}}$ (4) $(0.024$ $\mathrm{M} / 0.024 \mathrm{M})$ in $\left[\mathrm{D}_{8}\right]-\mathrm{Tol}$ at $298 \mathrm{~K}$. a) monitoring of reaction by ${ }^{1} \mathrm{H}$ NMR spectroscopy, b) First order plot of [1] vs time (min).

Table 2. Aryl Glycosides (2b-k) obtained by reaction of biaryl zinc reagents with $1^{[a]}$

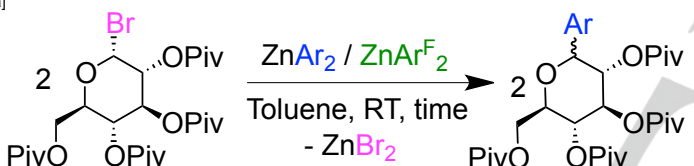

\begin{tabular}{|c|c|c|c|c|c|}
\hline Entry $^{[\mathrm{a}]}$ & $\mathrm{Ar}$ & Product & $\begin{array}{c}\text { Time } \\
\text { (h) }\end{array}$ & $\begin{array}{l}\text { Yield } \\
(\%)^{[b]}\end{array}$ & $\begin{array}{c}\beta / \alpha \\
\text { ratio }\end{array}$ \\
\hline 1 & 4- $\mathrm{MeC}_{6} \mathrm{H}_{4}$ & $2 b$ & 1 & 99 & $91 / 9$ \\
\hline 2 & 4-tBu- $\mathrm{C}_{6} \mathrm{H}_{4}$ & $2 c$ & 2.5 & 95 & $96 / 4$ \\
\hline 3 & 4-OMe- $\mathrm{C}_{6} \mathrm{H}_{4}$ & $2 d$ & 2 & 99 & $95 / 15$ \\
\hline 4 & $4-\mathrm{Cl}-\mathrm{C}_{6} \mathrm{H}_{4}$ & $2 e$ & 2 & 99 & $97 / 3$ \\
\hline 5 & 4-F-C $6 \mathrm{H}_{4}$ & $2 f$ & 2 & 98 & $94 / 6$ \\
\hline 6 & $4-\mathrm{CF}_{3}-\mathrm{C}_{6} \mathrm{H}_{4}$ & $2 g$ & 12 & $0^{[c]}$ & - \\
\hline 7 & 2-Me- $\mathrm{C}_{6} \mathrm{H}_{4}$ & $2 h$ & 1 & 97 & $98 / 2$ \\
\hline 8 & $2-\mathrm{OMe}-\mathrm{C}_{6} \mathrm{H}_{4}$ & $2 \mathbf{i}$ & $1^{[\mathrm{cl}}$ & 99 & $99 / 1$ \\
\hline 9 & $2,6-\mathrm{OMe}_{2}-\mathrm{C}_{6} \mathrm{H}_{4}$ & $2 j$ & 4 & 99 & $95 / 5$ \\
\hline 10 & 2-thienyl & $2 k$ & 2.5 & 93 & $95 / 5^{[d]}$ \\
\hline
\end{tabular}

[a]Conditions: $1(0.048 \mathrm{M}), \mathrm{ZnPh}_{2}(0.024 \mathrm{M}),\left[\mathrm{D}_{8}\right]-\mathrm{Tol}, 25^{\circ} \mathrm{C} .{ }^{[b]}$ Yields were determined by ${ }^{1} \mathrm{H}$ NMR spectroscopy using hexamethylcyclotrisiloxane as internal standard. ${ }^{[c]}$ Reaction was carried out at $85^{\circ} \mathrm{C}$. ${ }^{[d]} 4 \%$ of 3 -thienyl was observed.

Using these conditions, we next evaluated the scope of the reaction with different diaryl zinc reagents. Expanding the limited family of etherate-free organozinc reagents reported in the literature, we synthesized and characterised by NMR spectroscopy a series of diarylzinc compounds generated by initial lithium/halogen exchange and subsequent transmetallation with $\mathrm{ZnCl}_{2}$ in diethyl ether, followed by filtration to remove $\mathrm{LiCl}$ and evaporation of the ethereal solvent under vacuum. ${ }^{[10]}$ Without further purification, these zinc reagents were successfully coupled with 1 at room temperature in high yields and stereoselectivities (ratio $\beta / \alpha \geq 90: 10$ ). Electron-rich substituents at the aryl rings favoured the couplings, (Table 2, Entries 1-3), affording the corresponding $C$-glucoside in similar reactions times as when using reagents having electronwithdrawing substituents (Table 2, Entries 4 and 5) ${ }^{[10]}$ However, incorporation of the highly electron-poor trifluoromethyl group on the aryl ring inhibits the coupling reaction even under forcing reaction conditions $\left(110^{\circ} \mathrm{C}\right.$ ) (Table 2, Entry 6). ${ }^{[18]}$ In addition, this protocol proved to be compatible with steric hindrance, generating the ortho substituted desired coupled products $\mathbf{2 h}-\mathbf{2 j}$ (Table 2, Entries 7-9) at room temperature in excellent yields, in contrast with previous studies in which synthesis of the same $C$ glycosides required forcing reaction temperatures of $110^{\circ} \mathrm{C}^{[5 a]}$ Heteroaromatic zinc reagents can also be coupled, e.g. synthesis of $\mathbf{2 k}$, in $93 \%$ yield (Table 2, Entry 10).

\section{Step 1 anomeric oxocarbenium formation}

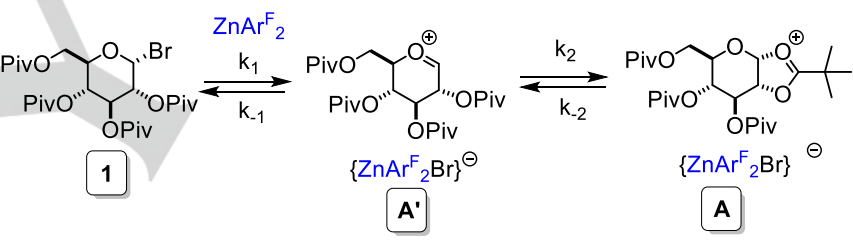

Step 2

zincate equilibrium

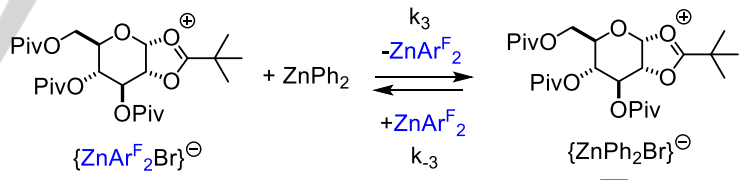

A

B

Step $3 \quad$ electrophilic Ar substitution

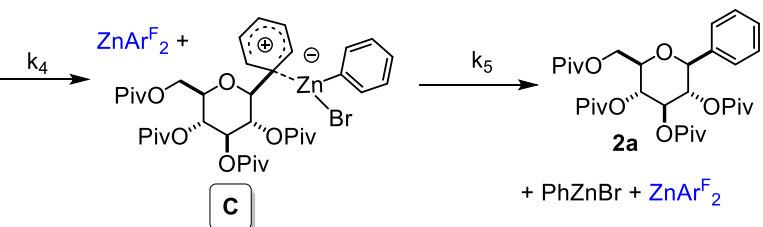

Scheme 1. Proposed 3-step mechanism of the investigated coupling reaction.

From a mechanistic perspective, these coupling processes can be postulated to occur via a multi-step process (Scheme 1) with initial bromide abstraction accomplished by Lewis acidic $\mathbf{4}$, giving rise to anomeric oxocarbenium ion $\mathbf{I}$ and zincate $\left\{\mathrm{ZnAr}_{2}{ }_{2} \mathrm{Br}\right\}$ (A in Scheme 1) via a kinetically invisible nonstabilized oxocarbenium species $\mathbf{A}^{\prime}$ (Scheme 1). Since $\mathrm{ZnPh}_{2}$ is also present in the reaction media, this species could be in equilibrium with zincate $\left\{\mathrm{ZnPh}_{2} \mathrm{Br}\right\}$ ( $\mathbf{B}$ in Scheme 1), and while this equilibrium would normally lie towards the left, giving the stronger Lewis acidity of $\mathbf{4}$, formation of a more nucleophilic 
$\left\{\mathrm{ZnPh}_{2} \mathrm{Br}\right\}$ species, capable of promoting a final, non-reversible, electrophilic aromatic substitution step (C in Scheme 1), should drive the reaction towards the generation of $\mathbf{2 a}$, along with $\mathrm{PhZnBr}$ and the recovery of 4 . The discrete Wheland intermediate $\mathbf{C}$ is suggested by the complete lack of reactivity of highly electron-deficient diarylzinc compounds (Table 2, entry 6), which would be consistent with the build-up of a positive charge in the arylation intermediate, although this is still to be confirmed experimentally and computationally. It should also be noted that under these conditions, NMR studies show that the Schlenk equilibrium affecting $\mathrm{PhZnBr}$ appears to be driven towards formation of $\mathrm{ZnPh}_{2}$ and $\mathrm{ZnBr}_{2}$ (Eq 2). ${ }^{[19]}$

$$
2 \mathrm{PhZnBr} \stackrel{\mathrm{ZnAr}_{2}}{=} \mathrm{ZnPh}_{2}+\mathrm{ZnBr}_{2}
$$

Kinetic studies using initial rates methods at $273 \mathrm{~K}$ offered some support to this mechanistic hypothesis. ${ }^{[10]}$ Thus, the reaction showed first order-dependence of bromosugar 1 (Fig S93, SI). Monitoring initial rates versus initial concentrations of both zinc reagents, 4 and $\mathrm{ZnPh}_{2}$, showed first-order behaviour but also displayed saturation in both cases (Figures S95-103, $\mathrm{SI})$. This is consistent with a rate-limiting oxonium formation under "normal" synthetic conditions (step 1, Scheme 1) at high concentration of $\mathrm{ZnPh}_{2}$, where $\mathrm{ZnPh}_{2}$ rapidly traps intermediate I forming $\mathbf{B}$ and subsequently $\mathbf{C}$. Contrastingly, at very low concentration of $\mathrm{ZnPh}_{2}$ or very high concentration of 4 , the C-C coupling is rate limiting (step 2), with return of intermediate $\mathbf{A}$ to the starting materials favoured over formation of intermediate B. $^{[20]}$

Finally, a brief discussion of the $\alpha / \beta$ ratios is in order. We were puzzled that our initial studies reported ${ }^{[5 a]}$ almost perfect $\beta$ stereoselectivity; whereas using neat toluene with or without $\mathbf{4}$ as catalyst yields around $90 \% \beta$ selectivity. The most glaring difference between the two sets of conditions is the presence or absence of extra bromide ion with respect to that provided by the bromosugar (as the $\mathrm{ZnAr}_{2}$ reagents were generated in situ via salt-metathesis with 2 eq of $\mathrm{LiAr}$ and $\mathrm{ZnBr}_{2}$ ). We carried out experiments with increasing concentrations of exogenous bromide, opting for tetrabutylammonium bromide (TBAB) instead of $\mathrm{LiBr}$ (used by Lemaire et al) ${ }^{[5 a]}$ owing to its much-improved solubility in toluene. We found that bromide ion did indeed improve selectivity while inhibiting the reaction. $\beta$-Selectivity increased, and reaction rate decreased with increasing bromide levels (Table 3).

Table 1. Direct arylation of 1 with $\mathrm{ZnPh}_{2}$ in the presence of $\mathrm{TBAB}^{[\mathrm{al}]}$.

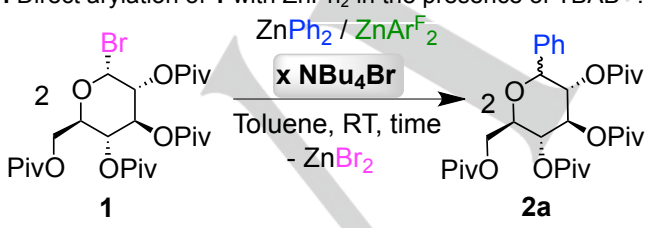

\begin{tabular}{ccccc}
\hline Entry & $\mathbf{x}$ eq & Time $(\mathbf{h})$ & ${\text { Yield }(\%)^{[a]}}^{\text {[a] }}$ & $\beta / \mathbf{\alpha}$ ratio \\
\hline $\mathbf{1}$ & 0 & 1 & 93 & $87 / 13$ \\
$\mathbf{3}$ & 0.25 & 5 & 98 & $92 / 8$ \\
$\mathbf{4}$ & 0.5 & 28 & 93 & $>99 / 1$ \\
$\mathbf{5}$ & 1 & $13^{[\mathrm{b]}}$ & 87 & $>99 / 1$
\end{tabular}

$\begin{array}{lccccc}{ }^{[a]} \text { Yields } & \text { were determined by } & { }^{1} \mathrm{H} & \mathrm{NMR} & \text { spectroscopy } & \text { using } \\ \text { hexamethylcyclotrisiloxane as internal standard }{ }^{[b]} \text { Reaction was carried out }\end{array}$ at $110^{\circ} \mathrm{C}$.

We explain the results as follows: the mechanism we have proposed refers exclusively to formation of the $\beta$ anomer. This pathway would not be plausible for the formation of the $\alpha$ anomer, which must be formed via the non-stabilized oxocarbenium ion A' (Scheme 2).

Indeed, the more stable intermediate $\mathbf{A}$ can only yield the $\beta$ anomer whereas $\mathbf{A}^{\prime}$ could lead to either $\alpha$ or $\beta$-product. It is plausible that $\mathbf{A}$ is so stable that it reacts only with the more reactive bromozincate ion pair $\mathbf{B}$, and $\mathrm{Ph}_{2} \mathrm{Zn}$ is not nucleophilic enough to couple with it. Although too poor a nucleophile to react with $\mathbf{A}, \mathrm{Ph}_{2} \mathrm{Zn}$ can react with $\mathbf{A}^{\prime}$, leading to mixtures of $\alpha$ and $\beta$. Clearly, due to the more favourable association of $\mathbf{4}$ with bromide ion $([\mathrm{A}]>[\mathrm{B}])$, there are always high concentrations of "free $\mathrm{Ph}_{2} \mathrm{Zn}$ " in solution, leading to some stereochemical leakage toward the " $\mathrm{Ph}_{2} \mathrm{Zn}$ pathway" and therefore some $\alpha$ anomer. Bromide has the effect of scavenging much of this $\mathrm{Ph}_{2} \mathrm{Zn}$, in addition to complexing 4 and slowing down the reaction. The result is predominant coupling via $\mathbf{B}$ and therefore mainly $\beta$ anomer.

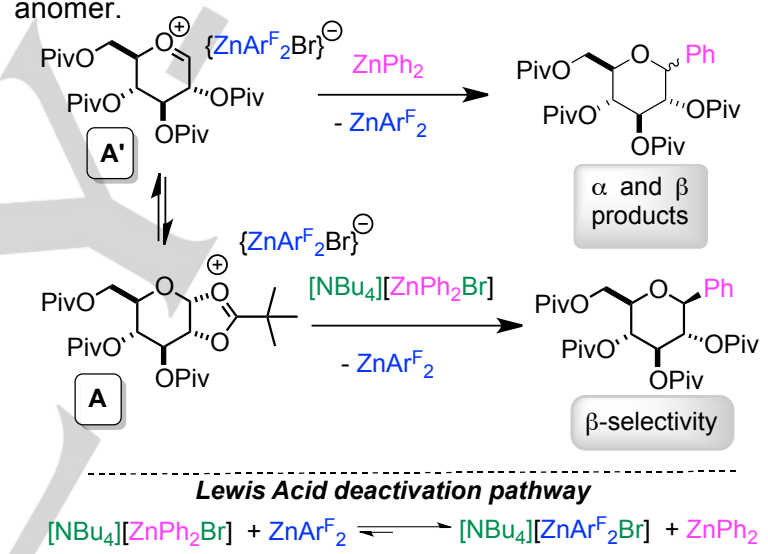

Scheme 2. Proposed rationale for the stereoselectivity observed in the presence of bromide anion.

In conclusion, we have disclosed a room-temperature, diastereoselective and functional-group tolerant $\mathrm{C}\left(\mathrm{sp}^{2}\right)-\mathrm{C}\left(\mathrm{sp}^{3}\right)$ bond formation methodology for the synthesis of $C$-glycosides. This involves cooperative arylation of glycosyl bromide 1 with the synergistic partnership of an aryl zinc and the non-arylating zinc reagent $\mathrm{ZnAr}_{2}{ }_{2}\left(\mathrm{Ar}^{\mathrm{F}}=\mathrm{C}_{6} \mathrm{~F}_{5}\right)$ (4). This methodology is strongly inhibited by the presence of donor solvents due to formation of coordination complexes of $\mathbf{4}$ as confirmed by NMR and titration studies. The addition of a promoter allows a much easier kinetic investigation, revealing a multi-step mechanism initiated by bromine abstraction promoted by $\mathbf{4}$, followed by bromide transfer to the arylating zinc reagent forming a more nucleophilic zincate, which ultimately undergoes an electrophilic aromatic substitution with the oxocarbenium electrophile, to form the new $\mathrm{C}-\mathrm{C}$ bond. Expanding the field of direct arylzinc coupling with electrophiles, these findings have established a new type of $\mathrm{Zn} / \mathrm{Zn}$ ' synergistic behaviour whose scope and applicability beyond glycosylation reactions are currently under investigation. 


\section{Acknowledgements}

We thank Dr. Pieter Westerduin and Dr. RajendraDeshpande for their support of this project. We also thank Dr. Dave Armstrong for his support on modelling the molecular volumes used in the DOSY NMR experiments.

Keywords: zinc $\cdot$ arylation $\cdot$ cooperative effects $\bullet$ transitionmetal free $\cdot$ zincate

[1] A. De Meijere, F. Diederich, Metal-Catalyzed Cross-Coupling Reactions, Wiley-VCH, Weinheim, 2004

[2] D. Haas, J. M. Hammann, R. Greiner, P. Knochel, ACS Catal, 2016, 6. 1540

[3] H. Minami, X. Wang, C. Wang, M. Uchiyama, Eur. J. Org. Chem. 2013 7891.

[4] H. Minami, T. Saito, C. Wang, M. Uchiyama, Angew. Chem. Int. Ed. 2015, 54, 4665.

[5] (a) S. Lemaire, I. N. Houpis, T. Xiao, J. Li, E. Digard, C. Gozlan, R. Liu, A. Gavryushin, C. Diène, Y. Wang, V. Farina, P. Knochel, Org. Lett. 2012, 14, 1480; (b) S. Barroso, S. Lemaire, V. Farina, A. K. Steib, R. Blanc, P. Knochel, J. Org. Chem. 2016, 81, 2804.

[6] J. J. Dunsford, E. R. Clark, M. J. Ingleson, Angew. Chem. Int. Ed. 2015 54, 5688.

[7] For some examples see:(a) E. C. Chao, R. R. Henry, Nat. Rev. Drug Discovery 2010, 9, 551; (b) P. Rawat, M. Kumar, N. Rahuja, D.S.L. Srivastava, A. Kumar, R. Maurya, Bioorg. Med. Chem. Lett. 2011, 21 228. (c) S. Nomura, S. Sakamaki, M. Hongu, E. Kawanishi, Y. Koga, T. Sakamoto, Y. Yamamoto, K. Ueta, H. Kimata, K. Nakayama, M. TsudaTsukimoto, J. Med. Chem. 2010, 53, 6355.

[8] ${ }^{13} \mathrm{C}$ NMR titration experiments allowed the calculation of the association constant (Keq) between $\mathrm{ZnPh}_{2}$ and DBE to give coordination adduct $\left[\mathrm{ZnPh}_{2}(\mathrm{DBE})\right]\left(K e q=2.33 \mathrm{M}^{-1}\right)$. See SI for details. In contrast, DOSY NMR studies have shown that in $\mathrm{d}_{8}$-toluene solution $\mathrm{ZnPh}_{2}$ exists as a dimer in equilibrium with its monomeric form, which is coordinatively unsaturated and could be expected to exhibit higher Lewis-acid reactivity.

[9] X-ray crystallographic studies showed $\left[\mathrm{ZnPh}_{2}(\mathrm{TMEDA})\right]$ exhibits a monomeric structure with TMEDA coordinated as a chelate to $\mathrm{Zn}$. This structure is retained in toluene $\left[\mathrm{D}_{8}\right]$-solutions (See $\mathrm{SI}$ for details).

[10] See SI for details

[11] ${ }^{1} \mathrm{H}$ NMR monitoring of the reaction of 1 with $\mathrm{ZnPh}_{2}$ showed only one set of aromatic signals, which progressively shift towards lower field at increasing conversions of $\mathbf{2}$. A similar trend has been previously noted for studies on THF solutions containing $\mathrm{EtZnCl}$ and $\mathrm{ZnEt}_{2}$, prepared by combining $\mathrm{ZnEt}_{2}$ and $\mathrm{ZnCl}_{2}$, see: A. J. Blake, J. Shannon, J. C. Stephens, S. Woodward, Chem. Eur. J., 2007, 13, 2462.

[12] Ammonium zincate complex 3 was obtained in a $86 \%$ isolated yield. DOSY NMR studies are consistent with the retention of its solid state structure (Fig 2) in deuterated toluene.

[13] ${ }^{13} \mathrm{C}$ NMR titration studies support product inhibition by the formation of coordination adduct $\left[\mathrm{ZnAr}_{2}{ }_{2}(2 \mathrm{a})\right]\left(K e q=25.21 \mathrm{M}^{-1}\right)$. It should also be noted that DOSY NMR experiments of solutions of $\mathrm{ZnPh}_{2}$ and 4 in $\left[\mathrm{D}_{8}\right]-$ toluene indicate that these two zinc compounds do not form a heteroleptic bis(aryl) [PhZnAr $\left.{ }^{F}\right]$ complex but exist as separate entities. See SI for details.

[14] ${ }^{13} \mathrm{C}$ NMR titration studies support formation of coordination adducts $\left[\operatorname{ZnAr}_{2}{ }_{2}(\mathbf{1})\right]$ and $\left[\operatorname{ZnAr}_{2}{ }_{2}(\mathrm{DBE})\right] \quad\left(K e q=13.53 \quad \mathrm{M}^{-1}\right.$ and $3.53 \quad \mathrm{M}^{-1}$ respectively), see $\mathrm{SI}$ for details.

[15] (a) H. Gong, M. R. Gagné, J. Am. Chem. Soc. 2008, 130, 12177; (b) H. Gong, R. Sinisi, M. R. Gagné, J. Am. Chem. Soc. 2007, 129, 1908.

[16] L. Nicolas, P. Angibaud, I. Stansfield, P. Bonnet, L. Meerpoel, S. Reymond, J. Cossy, Angew. Chem. Int. Ed. 2012, 51, 11101.
[17] Maximum concentration of $12.51 \mathrm{ppb} / \mathrm{mg}$ was observed for iron impurities. See supporting information for full details

[18] This contrasts with results reported when $\mathrm{ZnAr}_{2}\left(\mathrm{Ar}=4-\mathrm{CF}_{3}-\mathrm{C}_{6} \mathrm{H}_{4}\right)_{2}$ is used in the presence of $\mathrm{LiBr}$ which furnished the relevant coupling product in a $50 \%$ yield after $24 \mathrm{~h}$ at $110^{\circ} \mathrm{C}$. See reference [5a]

[19] ${ }^{1} \mathrm{H}$ NMR studies adding variable amounts of $\mathrm{PhZnBr}$ to a 1:1 mixture of $\mathrm{ZnPh}_{2}$ and $\mathbf{4}$ in $\mathrm{d}_{8}$-toluene using ferrocene as an internal standard have shown an increase in the concentration of $\mathrm{ZnPh}_{2}$ in solution, consistent with the Schlenk-type equilibrium being driven towards formation of $\mathrm{ZnPh}_{2}$ and $\mathrm{ZnBr}_{2}$. See $\mathrm{Sl}$ for details.

[20] By treating $\mathbf{B}$ and $\mathbf{C}$ as steady state intermediates, a rate law in agreement for these observations is shown in $\mathrm{SI}$. 
Entry for the Table of Contents (Please choose one layout)

Layout 2:

\section{COMMUNICATION}

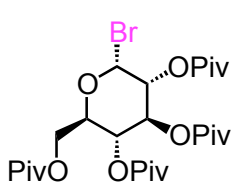

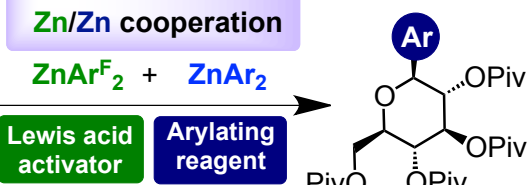

room temperature transition-metal free high yielding stereoselective

A dizinc glucose solution! Disclosing a new type of metal cooperation in organozinc chemistry, pairing a range of bis(aryl) zinc reagents $\mathrm{ZnAr}_{2}$ with the stronger Lewis acidic $\left[\left(\mathrm{ZnAr}_{2}{ }_{2}\right)\right]\left(\mathrm{Ar}^{\mathrm{F}}=\mathrm{C}_{6} \mathrm{~F}_{5}\right)$, enables highly stereoselective roomtemperature arylation of glycosyl bromides without using a transition metal catalyst.
A. Hernán-Gómez, S. A. Orr, M. Uzelac,

A. R. Kennedy, S. Barroso, X. Jusseau,

S. Lemaire, V. Farina* and E. Hevia*

Page No. - Page No.

Exploiting Synergistic Effects in Organozinc Chemistry for Direct Stereoselective C-Glycosylation Reactions at Room Temperature 